\title{
FUENTES Y CONTEXTO DEL MISTICISMO ESPAÑOL DEL SIGLO DE ORO
}

\author{
Manuel SUANCES MARCOS \\ Dpto. de Filosofía uned
}

1. Las fuentes: La herencia árabe, hebrea, mediterránea y renano-flamenca.

La mística española del Siglo de Oro no brotó como una planta por generación espontánea. Más bien es fruto de una rica síntesis que recoge una larga herencia cristiana, judía y musulmana. Nuestro suelo patrio ha sido durante muchos siglos escenario de convivencia y lucha entre diversas lenguas, religiones, espiritualidades y estilos de vida. El enfrentamiento medieval de las tres religiones produjo un extraordinario vigor en la fe y una alta ciencia teológica en cada una de ellas: primero en el Islam, luego en el mosaísmo y finalmente en el cristianismo. Esta influencia árabe y judía cobra especial relieve en lo religioso, no sólo por los libros, sino por el peso de la convivencia durante siglos. Las tres espiritualidades mantuvieron su fuerza vital en toda la Edad Media y compitieron entre sí por la existencia de instituciones similares como las órdenes militares en la zona árabe y cristiana y la lectura de la biblia en las sinagogas y las iglesias. El trilingüismo y trirreligionismo fue un fenómeno medieval típicamente

Endoxa: Series Filosoficas, $n^{\circ} 6,1995$, UNED, Madrid:

M.Suances Marcos: Fuentes y contexto del misticismo español del S. de Oro.

pp. 263-280. 
hispano. Existen todavía hoy ciudades como Córdoba, Granada, Albarracín, etc. que conservan sus barrios árabes, judíos y cristianos que son como la huella de aquella larga, problemática y fructífera convivencia que produjo una especial identidad y sincretismo ${ }^{1}$.

Andando el tiempo, España se abrió política y culturalmente al Mediterráneo, especialmente a Italia, con la que mantuvo estrechas relaciones religiosas y artísticas y más tarde con Carlos V, estuvo presente en los Países Bajos y en Alemania de donde vino el influjo de la devoción moderna y de la mística romano-flamenca. Desde mediados del Siglo XV, laneros de Castilla y Valencia, marineros de Huelva, políticos de Castilla y Aragón conectaron social, económica y universitariamente con países norteños y mediterráneos. Prevalecieron las relaciones políticas, comerciales, artísticas, literarias y espirituales con el sur de Francia, con Italia y Roma gracias a la política de la Corona de Aragón y al Papado. Cada uno de estos elementos tuvo su tiempo y su grado de influencia. Pero todos ellos ayudaron a los místicos españoles a descender a las raíces más profundas de lo humano y de lo cristiano, de lo esencial y de lo accesorio. Necesitaron criterios de identidad y discernimiento para diferenciar a fondo lo judío, lo mahometano, lo protestante, lo alumbrado.

Veamos un poco la influencia de cada una de estas herencias. Por lo que respecta a los árabes, su tradición mística se basa en la vida religiosa de los sufíes y en las obras literaria musulmanas conocidas por los teólogos y místicos españoles. Los sufíes incidieron como hombres religiosos en la sociedad musulmana española, harta de conquistas exteriores y olvidada de la vida interior.

La mística sufí se fundamenta en la experiencia de Dios, en saborear más que en saber, en la búsqueda interior más que en la lógica y el esfuerzo intelectual. Los sufíes fueron centinelas

\footnotetext{
${ }^{1}$ Andrés M., Historia de la mistica de la edad de oro en España y América, Madrid, Biblioteca de Átores Cristianos, 1994, p. 78.
} 
incansables de Dios. La sabiduría sufi no vive de la lógica sino de la quemadura de Dios que llama secretamente en la noche. Es una sabiduría de experiencia que no se adquiere con libros y estudios. Los sufíes desean entrar en el amor divino y sumergirse totalmente en él como respuesta a la llamada de Dios. Ello exige desasimiento del yo que tiene que simplificar su equipaje para vivir en espíritu. Distinguen la verdadera libertad frente a personas, cosas y normas, y no adoran a Dios por la esperanza de premio o castigo, sino que lo hacen por ser Dios quien es; también ellos hablan de la purificación del yo y de que sólo Dios basta, como repetiría luego Santa Teresa. Los grandes místicos del Islam y las vidas de algunos de sus santores andaluces influyeron en la mística española. Aben Abbad de Ronda, que murió en 1389, es considerado como un antecedente de la Noche oscura ${ }^{2}$. Y más tarde, en el siglo XV, Juan de Segovia elaboró un Alcorán en árabe, latín y castellano, verdadera biblia políglota cristiano-musulmana, medio siglo anterior a la biblia políglota Complutense. El había sido profesor de teología en Salamanca y había propiciado el diálogo pacífico sobre temas fundamentales de ambas religiones.

A su vez, la herencia judía viene determinada por la obras de Crescas, José Albo, Isaac Abravanel y otros teólogos hebreos que se movieron en la corriente del Talmud y de la Cábala. El libro del esplendor de Moisés ben Sentob, único libro postalmúdico aceptado por los judíos como canónico, influyó en la concepción de la observancia y pobreza de las órdenes medicantes españolas y de éstas en la renovación judía del siglo XV. Igualmente resulta claro el reflejo de la Cábala en autores españoles ${ }^{4}$. Pero la herencia judía más honda sobrevino por el movimiento de reforma interior judía en la España del siglo XV. En este siglo desaparece la convivencia de las tres religiones. El decreto de expulsión da lugar al fenómeno

\footnotetext{
2 Ibidem, p. 212.

${ }^{3}$ Cabanellas, O., Juan de Segovia y el planteamiento del problema islámico, Madrid, 1942.

'Secret, F., Les Kabalistes cliréntiens de la Renaissance, París, 1964.
} 
masivo de conversión al cristianismo, tanto de judíos -unos 150.000 - como de musulmanes. Estas conversiones fueron debidas a las persecuciones violentas, a los estatutos de sangre, a la predicación cristiana y a la reacción contra la corriente averroísta e increyente dentro de la sinagoga. Muchos judíos conversos justificaban su cambio religioso en el ceremonialismo y la multitud de preceptos legales judíos frente a la simplicidad de la ley cristiana del amor ${ }^{5}$.

Todo se agravó por la profunda desconfianza de los cristianos viejos hacia los conversos y la de los auténticos judíos hacia los conversos también. Los conversos verdaderos pasaron al cristianismo con toda la riqueza de su humanismo semita, con su espiritualidad veterotestamentaria, con su exégesis bíblica literal, y con la alegría de sustituir tantas leyes y ritos mosáicos por la única ley del amor a Dios y al prójimo.

Poco antes de la fecha de su expulsión (1492), surgió la mística del recogimiento $\mathrm{y}$, poco después, el movimiento de los alumbrados, conversos en su mayoría. En su interior aleteaba con fuerza la espiritualidad bebida en Sefer ha Zohar (Libro del esplendor), en los libros de Abulafia y otros autores. En cierto modo los alumbrados compartían ciertos rasgos con nuestros místicos, por lo cual éstos fueron confundidos con aquéllos y perseguidos.

Pero sin duda alguna la herencia de mayor perso en nuestros místicos es la mediterránea. Cuenta con un rico capital nutrido por la Sagrada Escritura, los Santos Padres, Dionisio Areopagita, San Agustín, S. Jerónimo, S. Basílio, S. Benito, S. Gregorio Magno, S. Bernardo, San Francisco de Asís y la Escuela Franciscana especialmente San Buenaventura, La escuela de San Víctor con Ricardo y Hugo, Santo Tomás de Aquino, Joaquín de Fiore, Gerson, Santa Catalina de Sena, y la tradicción benedictina, dominicana y agustina $^{6}$. Fue especialmente influyente San Buenaventura por su valoración de la experiencia del yo por encima de la ciencia, por

\footnotetext{
${ }^{5}$ Andrés, M.,op. cit., p. 80.

${ }^{6}$ Ibidem, p. 205.
} 
su visión de la unión inmediata con Dios sin mediación del entendimiento y por su reducción de las potencias al centro e integración del hombre.

Es quizá en este contexto donde conviene tratar aunque sea de pasada la tesis del neoplatonismo de nuestros místicos. Se ha dicho de ellos que eran neoplatónicos por dos conceptos, por su desprecio hacia lo corpóreo y por defender la unión ontológica con la divinidad. Pero ambas cosas no se corresponden con la realidad. Para ellos, el cuerpo no es frontera ni muro, sino posibilidad de comunicación. En su cristología, el cuerpo de Cristo, por deificción era sin duda también algo divino. La integración de cuerpo y alma y la reducción de los sentidos y potencias al centro desmiente esta tesis del neoplatonismo de la mística española. El pecado original desintegró la unidad psíquica del hombre y dió lugar a la acción independiente de sus fuerzas. En el ser desintegrado, cada elemento sigue su propio impulso; la madurez es jerarquizar esos elementos. En espiritualidad, esos elementos se han reducido a dos: cuerpo y alma, interno y externo, carne y espíritu. La superación de ese dualismo no siempre ha sido acertada, al hacer más hincapié en uno o en otro.

Platonismo y neoplatonismo relacionan accidentalmente cuerpo y alma; el alma aspira a liberarse del cuerpo para alcanzar la libertad. Ambos sitemas acentúan el dualismo.

Los místicos españoles no son filosóficamente platónicos. Para ellos, el hombre es un ser complejo, pero a la vez integrado en una naturaleza o principio de acción. Si que son dualistas los alumbrados, los erasmitas, los cartesianianos y los protestantes.

Los místicos españoles siguen una antropología que se sitúa entre el unitarismo y el dualismo integrándolos en el plano psicológico y teológico. El hombre tiene que elaborar y trabajar su integración; y así, salvada su unidad, la persona puede unirse con Dios. $Y$ ese trabajo se lleva adelante jerarquizando sentidos, potencias y centro: los sentidos deben obedecer a las potencias, éstas al centro, a la fe y a Dios. Esto es bien claro en la Subida al monte Carmelo y Noche: purificación de los sentidos y potencias 
para llegar a Dios por participación. La mística es ese camino que va desde la llamada de Dios hasta la unión participada en $\mathrm{El}^{7}$.

Por último la herencia germánica penetró en España por conductos políticos como la llegada de la dinastía de los Habsburgos mediante el matrimonio de Juana la Loca con D. Felipe el Hermoso y más tarde con Carlos $\mathrm{v}$ y el traslado de su corte a España; pero también por el flujo de estudiantes, comerciantes, artistas y religiosos entre Flandes y España. Las fuentes de la mística renano-flamenca son Santa Hildegarda, Santa Matilde de Magdeburgo, Jordán de Sajonia, Ulrico y Nicolás de Estrasburgo, el M. Eckhart, Taulero, Suso, David de Ausburgo, Ludolfo de Sajonia, Dionisio Cartujano, T. Kempis, Nicolás de Cusa y Angel Silesio ${ }^{8}$. Las obras principales de estos autores fueron traducidas al latín y publicadas por los cartujos de Colonia, en 1550. Estas fuentes germánicas dan lugar a la devoción moderna que rechazó planteamientos intelectuales y metafísicos. Basta recordar la postura del M, Eckhart sobre la posibilidad de establecer la identidad ontológica con Dios mientras el hombre se mantiene en este mundo; como también la conjunción que hace entre filosofía y teología poniendo la experiencia mística en el retorno a la deidad más que en la unión; con ello elimina el carácter personal haciendo que el alma se diluya como una gota en el mar de la divinidad. Dentro de este ámbito general, se pueden distinguir dos orientaciones en la mística medieval renano-flamenca: la del conocimiento de Dios por asimilación del amor y la intuición intelectual de la ciencia divina adaptada convenientemente a esta vida terrestre. La primera, más cultivada, se centra en la mística de la tiniebla. La segunda, menos cultivada, tiene una referencia trinitaria. Ambas se cruzan de modo experimental en San Juan de la Cruz'.

De todos modos, esta devoción moderna reaccionó frente al nominalismo y satisfizo los deseos de perfección de los religiosos;

\footnotetext{
${ }^{7}$ Ibidem, p. 326.

${ }^{8}$ Ibidem, p. 205.

9 San Juan de la Cruz, Cántico espiritual, canción 39.
} 
recomendó el cristianismo bíblico, de lenguaje sencillo y afectivo. Respondió a una necesidad europea después de la crisis científica y demográfica.

Esta es, a grandes rasgos, la rica herencia espiritual que recibieron los místicos españoles; veamos ahora el escenario geográfico y temporal en el que se desenvolvieron y que contribuyó también al desarrollo de esa semilla tan singular.

\section{El contexto histórico-geográfico español.}

El místico es también un hombre de su tiempo y desde éste pueden conocerse muchas de sus realidades. Dice un proverbio árabe que el hombre se parece más a su tiempo que a su padre. Pero antes de analizar aquella época histórica, digamos dos palabras acerca del marco geográfico. La mística del siglo XVI se expandió por toda España, Iberoamérica y Filipinas, pero nació y se fortaleció en Castilla. ¿Qué relación hay entre la mística y la geografía castellana?. La sobria y luminosa belleza de los parajes castellanos tienen que ver con Santa Teresa y San Juan de la Cruz. Dice A. Peers en su obra Spirit of flame $e^{10}$ que parece imposible que Juan de la Cruz pudiera haber nacido en otro sitio que en Castilla. Esos parajes le ayudaron a conocer mejor la persona. San Juan de la Cruz y Santa Teresa se sentían desterrados en Andalucía. Por otra parte Castilla estaba llena de conventos especialmente carmelitas: Valladolid, La Salceda, Avila, La Aguilera, El Abrojo... y tenía también el mayor número de Universidades, universitarios y facultades de Teología de toda Europa. Pero detrás de esos datos geográficos está el alma de Castilla hecha de valor, realismo, impulso de acción, virilidad y humanidad, pobreza y limpieza, alegría sin estruendo, virtud sin teatralidad, heroicidad callada,

\footnotetext{
${ }^{10}$ Peers, A., Spirit of flame, New York, 1944, p. 4.
} 
bondad sin artificios ${ }^{11}$. Esto es lo que provocó en Unamuno aquel entusiasmo por Castilla cuya esencia para él es una mezcla de estoicismo romano y de cristianismo que la hace ser sobria ante la prosperidad y paciente ante la adversidad.

El momento histórico en que aparece y se desarrolla la mística es el siglo de la hegemonía de España. ¿Por qué se produjo en España esta floración espiritual coetánea a su vez de un extraordinario despliegue en la política, en la milicia, en la economía, en la ciencia y en las artes?. Esta realidad se extiende desde los últimos años de la dinastía de los Trastámara hasta las primeras décadas de los Borbones.

España se sintió a si misma unida, capaz de empresas, llena de deseos y voluntad de realizarlos. No se trata de una hazaña aislada como la de conquistar un nuevo continente, sino la de ser la primera potencia de Europa. Hubo sentido de unidad y de empresa con la mejor preparación de entonces y con ánimo esforzado. El punto de partida está sin duda en la derrota definitiva del Islam y la conquista de Granada. Esta fue una verdadera hazaña. Hay que sopesar lo que supuso esto para un pueblo que había estado luchando durante siglos contra los árabes, ganando día a día su supervivencia y corriendo constantemente el peligro de extinción. ¡Qué concentración tan formidable de energía debía tener España en aquellos momentos! ¡Cómo debía pesar sobre su conciencia este cúmulo de fuerzas!. Los descubrimientos, los hallazgos creadores exigen tiempo, esfuerzo continuado, tesón y una larga preparación. Pues bien, España estuvo preparándose ocho siglos para este acontecimiento que la iba a dar una fortaleza tal que su identidad, no contenta con los propios límites patrios, se lanzó a la mayor empresa de los tiempos modernos: el descubrimiento de América y su incorporación a la cultura occidental. Pero la guerra de Granada superó además el individualismo de la nobleza; la campaña fue obra de un pueblo entero detrás de sus

${ }^{11}$ Reyes, A., Obras completas, VI, p. 329-330. 
Reyes; con minúsculas pero numerosas aportaciones, el pueblo sufragó los gastos de la guerra a través de la Bula Cruzada ${ }^{12}$.

Pero es la tensión acumulada durante siglos la que lanzó a España no a la conquista de nuevos mundos, sino a la expansión de su potente personalidad. España no fue allí a someter a otros pueblos, sino a hacerlos españoles y cristianos. Es preciso insistir en ello; esa identidad española ganada a pulso durante siglos era esencialmente cristiana.

A la vez que España luchaba por su supervivencia, luchaba también contra el infiel de modo que al mismo tiempo que se consolidaba como nación lo hacía desde la fe y contra el enemigo de la fe, el Islam. Era pues una única causa: la de su propio ser y la fe cristiana. Mientras el resto de Europa disfrutaba de ambas cosas en una cómoda retaguardia, España tenía que ganárselas día a día en el frente de vanguardia. Así se explica que esa fortaleza de su identidad se ensanchase en un nuevo mundo y así se explica también que mientras en el resto de Europa se expandían el humanismo renacentista de corte pagano y la ruptura de la unidad religiosa, España, sin dejar de abrirse a las nuevas corrientes modernas que postulaban la emancipación de la conciencia, fuese no sólo capaz de mantener su fe, sino de armonizarla con los nuevos tiempos. $Y$ es que su religiosidad era tan sólida que impregnaba no sólo sus estructuras externas, sino su vida entera sin por ello cerrarse a las corrientes modernas. Por eso, mientras la modernidad en Europa fue pagana o protestante, en España siguió siendo católica.

Desde esta perspectiva se entiende mejor la expansión de España en América y su evangelización. ¿Cómo se explica que un país poco poblado, como era España entonces, que no superaba los diez millones de habitantes se apoderase de casi todo el continente americano en unos cincuenta años?. Aquel puñado de hombres aguerridos pobló ciudades, campos, pueblos y sierras; surcó mares, océanos y ríos en condiciones indescriptibles. ¿Qué hay debajo de

${ }^{12}$ Andrés, M., op. cit., p. 76 
la decisión de Cortés de quemar las naves, o de la de Orellana en el primer recorrido del Amazonas o de la de Valdivia en ir a Chile?. No cabe duda que aplicando el criterio de Bergson hay que decir que eran tipos fuertes, vitalmente superiores, puntos de concentración de una inmensa energía. Eran unos "quijotes» embarcados en una empresa que les desbordaba pero que respondía plenamente a las ansias de expansión y de fe que bullían en España.

Pero esta apertura de España era la de una sociedad típicamente abierta. España no sólo se abrió al Atlántico y al Pacífico, sino que se abrió al Mediterráneo y a Europa y en un orden interno de cosas, como veremos más adelante, se abrió también a las reformas de Renacimiento y del Humanismo. En España latía un espíritu universal.

En las Universidades que fundó en las diversas ciudades de América no se enseñaba teología o literatura española. Se explicaba en latín la teología de la Sacra doctrina siguiendo el modelo de la Universidad de Salamanca y se enseñaba la prosa y poesía de Horacio, Virgilio, Cicerón y los clásicos; no se enseñaba la literatura del Cantar de mío Cid, o la poesía de Jorge Manrique. Pero no sólo eso. La apertura y universalidad de la sociedad española se muestra además en el mestizaje. Los españoles se mezclaron y casaron con los indígenas, cosa que no hicieron otros conquistadores europeos; el ideal de entrega y solidaridad interhumana llevada a cabo por España se tradujo en la creación del derecho internacional y el derecho indiano atizados también desde la Universidad de Salamanca. De las bases de ese derecho internacional, nacido al filo de la aparición del nuevo mundo, todavía vivimos hoy. Es cierto que en toda obra humana hay luces y sombras; España no fue una excepción. También hubo aprovechados y depredadores, pero la autocrítica que hizo España de si misma respecto a su acción en América ¿en qué país europeo conquistador ha tenido lugar? ¿Se puede imaginar una leyenda negra en Inglaterra por ejemplo? ¿Hay algún Fray Bartolomé de las Casas en cualquiera de los países europeos conquistadores?. 
A su vez la expansión política era hermana de la misionera. Ese país semipoblado que era España fue capaz de regalar a América 15.000 misioneros que dieron su saber y su vida por aquellos indígenas. Civilización y cristianización fueron inseparables en el nuevo mundo. El misionero español en América es una de las grandes realizaciones humanas de las historia universal. Trabajó gratuitamente, respetó las conciencias, promovió el contacto pacífico. Este espíritu misionero fue a la vez exponente y acicate de la vida espiritual española. Pero ¿quién sostenía esta tensión de misioneros y descubridores?. Los místicos. La mística española era el verdadero núcleo desde donde se expandían como de un fuego central todas estas aventuras. La aventura de los místicos era esa intensa búsqueda de Dios antes descrita; pues bien, esta búsqueda corre paralela con la de nuevas tierras, mares, hombres, universidades. Un hábito común, universal y cristiano, las traspasa a todas ellas como manifestaciones de un mismo espíritu. Valga como muestra un pequeño ejemplo. En medio de sus noches internas y su soledad claustral, Santa Teresa sigue con enorme interés las peripecias de sus hermanos que se embarcaron a América y mientras uno de ellos perdía su vida en las reyertas de Pizarro en el Perú, la Santa se debatía en la reforma del Carmelo. Estaban luchando por los mismos ideales, en la misma empresa, aunque hubiese por medio un océano y miles de kilómetros de distancia.

Pero miremos un poco hacia dentro y fijémonos en lo que ocurre en la España peninsular. Los Reyes Católicos habían logrado la unidad política y religiosa de España. Más tarde hubo un cambio de política internacional en el imperio de Carlos v. Estuvo a punto de venirse abajo la recién lograda unidad a causa de la guerra de las comunidades. ¿Fueron los comuneros una sociedad cerrada?. Parece que en ellos prendió el nacionalismo castellano que quería circunscribirse al ámbito y tradicción de la vieja Castilla. Es cierto que Carlos v engrosó en exceso su corte con gentes de Flandes y Alemania, pero isintieron los comuneros amenazada su identidad ante la apertura que suponía hacia 
Europa la nueva forma y orientación de Carlos V? ¿La guerra de las comunidades no fue un paso hacia atrás?.

Desde los Reyes Católicos hasta Felipe II, España hizo la reforma del episcopado, del clero, de los religiosos, de la universidad; se saneó el ambiente de corrupción y poder. Cisneros, con sus dos regencias, supo soldar los hiatos que aparecieron en la sucesión monárquica. España salvó también el escollo de las guerras con Portugal, nación hermana que tenía unos ideales nacidos al calor de España, pero con la que disfrutaba la hegemonía del nuevo mundo.

\section{El contexto social.}

Pero ciñéndonos ahora al ámbito de la espiritualidad de aquel momento del cual nació la mística, hay que subrayar que en toda Europa se había extendido desde el Renacimiento un humanismo que había dado al traste con la espiritualidad medieval; ésta había sido objetiva y especulativa, había dado primacía a las estructuras sobre la persona; en cambio la espiritualidad del siglo XV y XVI acentúa los planteamientos del hombre y de la propia experiencia; es más interior y subjetiva, más experiencial ${ }^{13}$. El ambiente humanista heredado de L. Valla, Cusa, Ficino, etc. canta la dignidad del hombre como ser individual y libre, como un microcosmos. Este nuevo ideal de hombre libre e independiente cuya referencia última es la conciencia fue lo que dió lugar al Humanismo renacentista, al luteranismo, calvinismo, erasmismo y en España a esos movimientos peculiares que fueron los alumbrados y los reformadores de las órdenes religiosas. Todo esto ayudó a amasar la mística española: ella supo asimilarlas con gran sentido de integración. Fueron tiempos recios al decir de Santa

${ }^{13}$ Ibidem, p. 61 
Teresa. Veamos cada uno de ellos en particular y su papel en torno a la mística.

- El luteranismo llegó a España primeramente como motivo de un nuevo y valiente intento de reforma, y más tarde como vivencia y doctrina. Lutero despertó entusiasmo y muchos grupos de aragoneses, castellanos y andaluces abrazaron su doctrina. Carlos $\mathrm{V}$ y Felipe II por un lado y la inquisición por otro reprimieron con dureza este movimiento como lo prueban los famosos autos de fe de Valladolid y Lérida. Esta doctrina llegó a España en el momento más creativo y deslumbrante de nuestra historia; y España reaccionó contra ella desde el proyecto de su unidad realizada por los Reyes Católicos ${ }^{14}$.

- Los erasmitas querían restaurar el cristianismo en toda su pureza. Pero Erasmo era escéptico, intelectual y lejano; buscaba paz y convivencia a través de la tolerancia y perseguía un fin educativo mas que una radical exigencia evangélica. Su rasgo era la áurea mediocridad; no se empeñó en escalar las cimas de la unión con Dios ; gustó pero no arrastró. Dejaba el alma seca; por eso se le estudia, no se le lee; le falta el calor penetrante de Lutero o de Santa Teresa. La reforma consistía en una vuelta a la fuentes: La Sagrada Escritura y la interioridad; para llevarlo a la práctica escogió dos caminos: la crítica y la ciencia. Su crítica resulta amarga y envenenada y se queda en un plano meramente destructivo, desprestigiando el método escolástico, la vida monacal y el ritualismo. El aspecto positivo de esta crítica es la valoración que hace de lo interno; pero la exclusión exhaustiva que hace de lo externo, deja el seguimiento de Cristo reducido a una mera imitación moral sin llegar a una auténtica transparencia. Esta desvaloración de lo externo chocó con la mística que da importancia a lo externo como parte esencial del hombre. $Y$ su ideal humanista se enfrentó también a Lutero por el sumo valor que

\footnotetext{
${ }^{14}$ Ibidem, p. 292 y ss.
} 
daba a la libertad frente al pobre papel que ésta tenía en el luteranismo ${ }^{15}$.

- Los alumbrados fueron una realidad típicamente hispana. Los inquisidores los consideraron hijos de los begardos. No fueron hombres de letras y cultivaron un secretismo que promovía el amor puro sin necesidad de obras. El capítulo franciscano de Castilla los define así: «una peste herética blanda, pero persuasiva llamada de los alumbrados o vía iluminativa o de los que se dejan a la disposición divina y no quieren hacer nada a no ser que se les sugiriese debidamente por inspiraciones o revelaciones divinas". El ambiente en que se movían era de amistad cerrada y estrecha, sentimiento de autoperfección, autodefensa vigilante, estilo secreto. Se consideraban a si mismos perfectos, autosuficientes, seguros de su salvación; despreciaban a los activos, se creían libres de todo mandato, juzgaban todo, pero nadie podía juzgarles a ellos por ser hombres de espíritu. Se instalaban en la iluminación y el amor de Dios, despreciando el resto de los mandamientos. Se les reputó como una secta con todos las consecuencias ideológicas y sociales que eso comportaba. Pero hay que comprenderles también; en su mayoría eran hijos de judíos conversos y no puede olvidarse la soledad social y religiosa de estos hombres en la España de principios del XVI. Calaron a fondo en el reino de Toledo, sobre todo en Ciudad Real. Ellos tocaron muchas fibras religiosas populares; impactaron al pueblo; contaron con el ambiente subjetivo europeo, espiritual y contemporáneo. Constituyeron una especie de reflejo sombrío y mala inteligencia de la mística española ${ }^{16}$.

Luteranos, erasmitas y alumbrados proyectaron la reforma de la vida religiosa superando el sentido legalista de la propia regla, del culto exterior, de la religiosidad mecanizada y cuantificada, llenándolo todo de espíritu. Pero descuidaron el valor del cuerpo, de lo exterior, de la actividad humana. A su vez, los escolásticos

\footnotetext{
${ }^{15}$ Ibidem, p. 281 y ss.

${ }^{16}$ Ibidem, p. 274 y ss.
} 
de las universidades españolas se enfrentaron a ellos y a los místicos primando la ciencia sobre la experiencia, la objetividad sobre la interioridad. Es este otro frente en el que se vieron involucrados los místicos. Francisco de Vitoria no entiende la nueva espiritualidad de los místicos que es más afectiva y personal y menos objetiva. Melchor Cano dirá: «Es gran locura en cosas nuevas y dudosas arrojarse los hombres a aprovecharlas y santificarlas, dejando los caminos llanos y seguros, que mil quinientos años, ha la Iglesia tenido» ${ }^{17}$.

Las reservas de los escolásticos frente a los místicos las recoge bien Juan de la Cruz, O.P. discípulo de Vitoria al decir que reconoce su vitalidad pero que teme sus exageraciones e imprecisiones. Estas objeciones fueron dardos envenenados contra Santa Teresa y S. Juan de la Cruz a manos de Melchor Cano. Y es que la teología escolástica era en exceso lógica y sutil. Los místicos en cambio buscaron ardientemente el contacto directo con Dios, cálido, consolante, accesible a todo hombre. Cisneros intentó mediar entre escolástica y mística para llegar a una única teología y espiritualidad, pero las diferencias fueron profundas desde el punto de vista psicológico y cristológico y la deseada unidad no llegó a producirse.

\section{Síntesis de los místicos españoles.}

Llegados ya al punto final, es el momento de percibir la ingente síntesis que hicieron los místicos españoles. Bajaron al centro sustancial del hombre donde integraron cuerpo y alma, sentidos y potencias. Alcanzaron un ideal de hombre que se construye desde si mismo con una clara conciencia de fe cristiana; desde él impregnaron la vida española y superaron la herencia judía y musulmana. Simplificaron los métodos recargados de la devoción

${ }^{17}$ Caballero, F., Conquenses ilustres, Melchor Cano, Madrid, 1871, p. 500 
moderna y desideologizaron algunos aspectos de la mística renano-flamenca. Unieron lo natural y lo sobrenatural; de ahí su cercanía al humanismo renacentista, pero lo hicieron desde el Evangelio; es decir, unieron el ideal humanista que hace del hombre lo esencial, con el ideal cristiano que proclama el amor de Dios al hombre y que pone en el centro del alma su morada. En ese sentido la mística española conecta de lleno con el humanismo pero se libera de la preocupación de éste por la pura forma literaria y por la idolatría del método. Empatizaron igualmente con el luteranismo por el sentido de la autonomía del hombre, la libertad y el valor de la interioridad frente a la norma; pero se distanciaron de él porque el hombre no está completamente corrupto y por consiguiente ha de cooperar necesariamente para alcanzar la perfección y la salvación.

Por eso armonizaron la respuesta libre del hombre y la iniciativa divina, sabiendo que Dios lleva la parte principal y la respuesta humana es más pasiva. Cierto que ambos, Luteranismo y mística española vieron necesaria la reforma de la Iglesia tras el secular encorsetamiento institucional de ésta. Pero mientas el luteranismo rompe con la Iglesia y hace la reforma desde fuera, los místicos lo hacen desde dentro. Por eso el interiorismo que en Europa llevó al Luteranismo y al Calvinismo, en España condujo a la mística como cima de la Reforma.

Los místicos cultivaron la unión con Dios hasta el máximo, pero no se autodivinizaron como los alumbrados ni se replegaron como ellos en grupos cerrados, ni desvalorizaron la aportación del trabajo y del conocimiento humano. Coincidieron con los erasmistas en la primacía del valor interno de la acción frente al mero cumplimiento de la ley; valoraron igualmente el conocimiento, pero no hicieron de él un valuarte independiente. Esto se ve bien claro en Santa Teresa. Ella sufre de no haber estudiado más a fondo letras y lo mismo quiere para sus monjas; pero al lado de esta valoración está el aviso constante de subordinar ese conocimiento a la búsqueda de Dios; de lo contrario ella lo ve como especialmente destructor. Tampoco se quedaron en la mera crítica 
que conduce a la sequedad como les ocurrió a los erasmistas, sino que se guardaron bien de la crítica empezando ésta por ellos mismos.

Sus relaciones con la Escolástica fueron mas sutiles: la mayoría de los místicos conocieron y estudiaron la filosofía y teología escolástica, pero dieron prioridad a la experiencia de Dios sobre la ciencia deductiva que era el principio básico de aquélla. Primaron el amor y la voluntad sobre el conocimiento especulativo creando un interiorismo que se hizo sospechoso para la Escolástica. Además los místicos basaron su piedad en un contacto directo con la Escritura que estaba más acorde con el moderno biblicismo promovido por Cisneros y Lutero. Lo cual hizo aumentar los sospechas sobre ellos.

Así pues anduvieron en el filo de todas las doctrinas y por ello fueron confundidos y atacados. Los teólogos de Salamanca los confundían con los alumbrados; éstos los consideraban ortodoxos cercanos a la Escolástica. Los humanistas los consideraron tradicionales, los luteranos también. La inquisición los tenía por luteranos, alumbrados o erasmistas. Recibieron críticas de todos, pero ellos respondieron con la característica típica del místico: la bondad.

Así pues los místicos españoles anduvieron siempre entre antitesis: entre interioristas y exterioristas, activistas y quietistas, entre partidarios de la pura experiencia y los del conocimiento conceptual, entre activos y contemplativos, entre partidarios de la fe y de las obras, entre ascéticos y místicos, entre impecabilidad del hombre y corrupción esencial de la naturaleza, entre melancólicos de un pasado y utópicos de un futuro imposible; entre rechazo y divinización de la regla.

En síntesis, la genialidad de la mística española radica en su antro-teocentrismo. Bajaron a lo más hondo de la «Psijé» humana y allí lograron la máxima personalización, la suma realización de la conciencia personal trascendente; acercaron lo más posible el hombre a Dios sin caer en el panteísmo y, al hacer esto, se enmarcaron en la concepción antropológica de la persona humana 
que en España va desde Gregorio de Elvira y el priscilianismo, pasando por los grandes teólogos franciscanos y dominicos medievales, hasta sus propios días. 